OPEN ACCESS

Edited by:

Graeme Clive Hays,

Deakin University, Australia

Reviewed by:

Gail Schofield

Queen Mary University of London,

United Kingdom

Richard Reina,

Monash University, Australia

*Correspondence:

Vinay Udyawer

v.udyawer@aims.gov.au

Specialty section:

This article was submitted to

Marine Megafauna,

a section of the journal

Frontiers in Marine Science

Received: 23 July 2018 Accepted: 10 October 2018 Published: 06 November 2018

Citation:

Udyawer $V$, Barnes $P$, Bonnet $X$ Brischoux F, Crowe-Riddell JM,

D'Anastasi B, Fry BG, Gillett A, Goiran C, Guinea ML, Heatwole H, Heupel MR, Hourston M, Kangas M, Kendrick A, Koefoed I, Lillywhite HB, Lobo AS, Lukoschek V, McAuley R,

Nitschke $C$, Rasmussen $A R$, Sanders KL, Sheehy C III, Shine R,

Somaweera R, Sweet SS and Voris HK (2018) Future Directions in the Research and Management of Marine Snakes.

Front. Mar. Sci. 5:399. doi: 10.3389/fmars.2018.00399

\section{Future Directions in the Research and Management of Marine Snakes}

\author{
Vinay Udyawer ${ }^{1 *}$, Peter Barnes ${ }^{2}$, Xavier Bonnet ${ }^{3}$, François Brischoux ${ }^{3}$, \\ Jenna M. Crowe-Riddell'4, Blanche D'Anastasi5,6, Bryan G. Fry ${ }^{7}$, Amber Gillett ${ }^{8}$, \\ Claire Goiran ${ }^{9}$, Michael L. Guinea ${ }^{10}$, Harold Heatwole ${ }^{11}$, Michelle R. Heupel12, \\ Mathew Hourston ${ }^{13}$, Mervi Kangas ${ }^{13}$, Alan Kendrick ${ }^{14}$, Inigo Koefoed ${ }^{13}$, \\ Harvey B. Lillywhite ${ }^{15}$, Aaron S. Lobo ${ }^{16}$, Vimoksalehi Lukoschek ${ }^{17}$, Rory McAuley ${ }^{13}$, \\ Charlotte Nitschke ${ }^{4}$, Arne R. Rasmussen ${ }^{18}$, Kate L. Sanders', Coleman Sheehy III'19, \\ Richard Shine ${ }^{20}$, Ruchira Somaweera ${ }^{21}$, Samuel S. Sweet ${ }^{22}$ and Harold K. Voris ${ }^{23}$
}

${ }^{1}$ Australian Institute of Marine Science, Darwin, NT, Australia, ${ }^{2}$ Parks and Wildlife Service, Department of Biodiversity, Conservation and Attractions, Exmouth, WA, Australia, ${ }^{3}$ CNRS, Centre d'Etudes Biologiques de Chizé, UMR 7372, Université de La Rochelle, La Rochelle, France, ${ }^{4}$ School of Biological Sciences, The University of Adelaide, Adelaide, SA, Australia, ${ }^{5}$ College of Science and Engineering, James Cook University, Townville, QLD, Australia, ${ }^{6}$ AIMS@JCU, Australian Institute of Marine Science and James Cook University, Townsville, QLD, Australia, ${ }^{7}$ School of Biological Sciences, The University of Queensland, Brisbane, QLD, Australia, ${ }^{8}$ Australia Zoo Wildlife Hospital, Beerwah, QLD, Australia, ${ }^{9}$ Labex Corail, Université de la Nouvelle-Calédonie, Nouméa, New Caledonia, ${ }^{10}$ Research Institute of the Environment and Livelihoods, Charles Darwin University, Darwin, NT, Australia, ${ }^{11}$ Department of Zoology, University of New England, Armidale, NSW, Australia, ${ }^{12}$ Australian Institute of Marine Science, Townsville, QLD, Australia, ${ }^{13}$ Department of Primary Industries and Regional Development, Perth, WA, Australia, ${ }^{14}$ Marine Science Program, Department of Biodiversity, Conservation and Attractions, Kensington, WA, Australia, ${ }^{15}$ Department of Biology, University of Florida, Gainesville, FL, United States, ${ }^{16}$ Independent Researcher, Salvador Do Mundo, India, ${ }^{17}$ ARC Centre of Excellence for Coral Reef Studies, James Cook University, Townsville, QLD, Australia, ${ }^{18}$ The Royal Danish Academy of Fine Arts, Schools of Architecture, Design and Conservation, Copenhagen, Denmark, ${ }^{19}$ Division of Herpetology, Florida Museum of Natural History, University of Florida, Gainesville, FL, United States, ${ }^{20}$ School of Life and Environmental Sciences, The University of Sydney, Sydney, NSW, Australia, ${ }^{21}$ Ecosystem Change Ecology Team, CSIRO Land and Water, Floreat, WA, Australia, ${ }^{22}$ Department of Ecology, Evolution, and Marine Biology, University of California, Santa Barbara, Santa Barbara, CA, United States, ${ }^{23}$ Department of Zoology, Field Museum of Natural History, Chicago, IL, United States

Marine snakes represent the most speciose group of marine reptiles and are a significant component of reef and coastal ecosystems in tropical oceans. Research on this group has historically been challenging due to the difficulty in capturing, handling, and keeping these animals for field- and lab-based research. Inexplicable declines in marine snake populations across global hotspots have highlighted the lack of basic information on this group and elevated multiple species as conservation priorities. With the increased interest in research on marine snakes, we conducted a systematic survey of experts to identify twenty key questions that can direct future research. These questions are framed across a wide array of scientific fields to produce much-needed information relevant to the conservation and management of marine snakes.

Keywords: conservation, endangered species, management, policy, research priorities, sea snake, sea krait

\section{INTRODUCTION}

Marine snakes are an ecologically diverse group that represent multiple evolutionary transitions from a terrestrial to aquatic mode of life (Sanders et al., 2013). This includes estuarine and coastal Asian water snakes of the family Homalopsidae, file snakes (Acrochordidae), amphibious sea kraits (Elapidae, Laticauda) and completely marine 'true' sea snakes (Elapidae; Aipysurus and 
Hydrophis) (Pyron et al., 2013). Marine snakes are geographically widespread and speciose ( $>100$ species), comprising a critical component of reef and coastal ecosystems in tropical and subtropical waters of the Indian and Pacific oceans (Rasmussen et al., 2011). Currently, we know much less about the ecology of marine snakes than almost any other major radiation of reptiles, reflecting logistical obstacles to research (Bonnet et al., 2016). For example, little is known for most species about mating systems, lifetime reproductive success, population connectivity and capacity for recovery following declines. Currently, much of our understanding of marine-snake biology is based primarily on inference rather than on rigorous empirical data.

Scientific interest in marine snakes has steadily increased since the 1950s, with multiple influential publications driving the focus and direction of research on this group (Dunson, 1975; Heatwole, 1999). Early research focused on descriptive studies, field observations and general biology of snakes predominantly in the hydrophiine subfamily (Figure 1). As interest developed, alongside advances in field and laboratory techniques, research on marine snakes has progressed to exploring complex evolutionary questions, physiology, toxinology, ecology, behavior, and resolution of systematics amongst the broader clades. Recent inexplicable population declines of marine snakes across multiple global hotspots have raised concerns about multiple species within this group, with focused research needed to understand causes and extent of declines (Goiran and Shine, 2013; Guinea, 2013; Lukoschek et al., 2013). The lack of fundamental information and long-term monitoring of marine snakes has made managing and conserving populations difficult.

Achieving the daunting task of filling key gaps in the knowledge of marine snakes to support effective management and conservation with limited availability of resources, requires a strategic approach (Sutherland and Woodroof, 2009). We conducted a survey of the research and management community to identify important questions to define future directions in the research and management of marine snakes. These questions are framed within a wide array of fields including evolutionary biology, ecology, toxinology, and animal health, which provide a roadmap for future marine-snake research and produce information relevant for conservation and management.

\section{METHODS}

A survey was conducted to identify key questions to shape future directions in research on marine snakes. The survey was structured similar to previous studies (e.g., Sutherland et al., 2013; Hays et al., 2016). Firstly, invitations were sent out to research scientists and managers who have significant experience and interactions with marine snakes. We endeavored to include those with expertise in a wide array of fields to capture multiple aspects of research needs. Each participant was asked to propose up to five ranked questions that could be used to advance research on marine snakes in general as well as in particular fields. Reponses were compiled, with similar questions pooled, and a full list of questions collated. Participants were then provided the full list of questions and asked to rank them and confirm that they accepted how questions were framed. Responses, comments, and rankings were tallied and aligned with predominant themes. Brief discussions associated with each question presented here are the result of comments and responses provided by participants in the survey.

\section{RESULTS AND DISCUSSION}

The survey of research scientists and managers resulted in identification of twenty questions that participants considered important and that would lead to progress in research on marine snakes (Table 1). The twenty questions were classed within six themes. Each question was framed broadly and addressed fundamental gaps in knowledge and key information needed by managers and policy makers. We list these questions within each of the six themes and provide a brief discussion of how the questions can shape future research on marine snakes.

\section{Theme 1: Biology, Ecology, and Physiology}

\section{What are the geographic distributions and boundaries of the species of marine snakes, and where are hotspots of biodiversity, endemism, and richness?}

Defining the geographic distribution and boundaries of species is an important component in understanding populations, assessing risk from threatening processes, and facilitating conservation (Marshall et al., 2014; Heatwole et al., 2017). Improved spatial data for marine snakes is required to: (i) establish baseline 'areas of occupancy,' 'extent of occurrence,' and species boundaries, especially for data-deficient and threatened species (key criteria for assessing conservation status); (ii) identify hotspots of diversity and endemism; and (iii) enable reliable modeling of species distributions under current and future climates.

Currently, geographic distributions of most marine species of snakes are poorly defined, especially for data-deficient (34\% of recognized species) and endemic species with small ranges (Elfes et al., 2013). Some species are only known from very restricted areas, with few individuals being recorded (e.g., Hydrophis sibauensis and $H$. parviceps; Rasmussen et al., 2001, 2012). A recent example of the insufficiency of distributional data is from two species of hydrophiine snakes (Aipysurus apraefrontalis and A. foliosquama) that were presumed extinct from their previously known geographic ranges (i.e., restricted to the offshore Ashmore Reef system in Western Australia; Lukoschek et al., 2013). Recent studies have revealed overlooked populations scattered in coastal locations $>800 \mathrm{~km}$ from their previously known range (Sanders et al., 2015; D’Anastasi et al., 2016). These previously unknown populations occur close to major infrastructural developments and are impacted by incidental capture by trawl fisheries (Kangas et al., 2015a,b). The existence of additional populations can dramatically change species' status and threat level.

The paucity of data on marine snake distributions at a species level has resulted in assignment of a conservation 


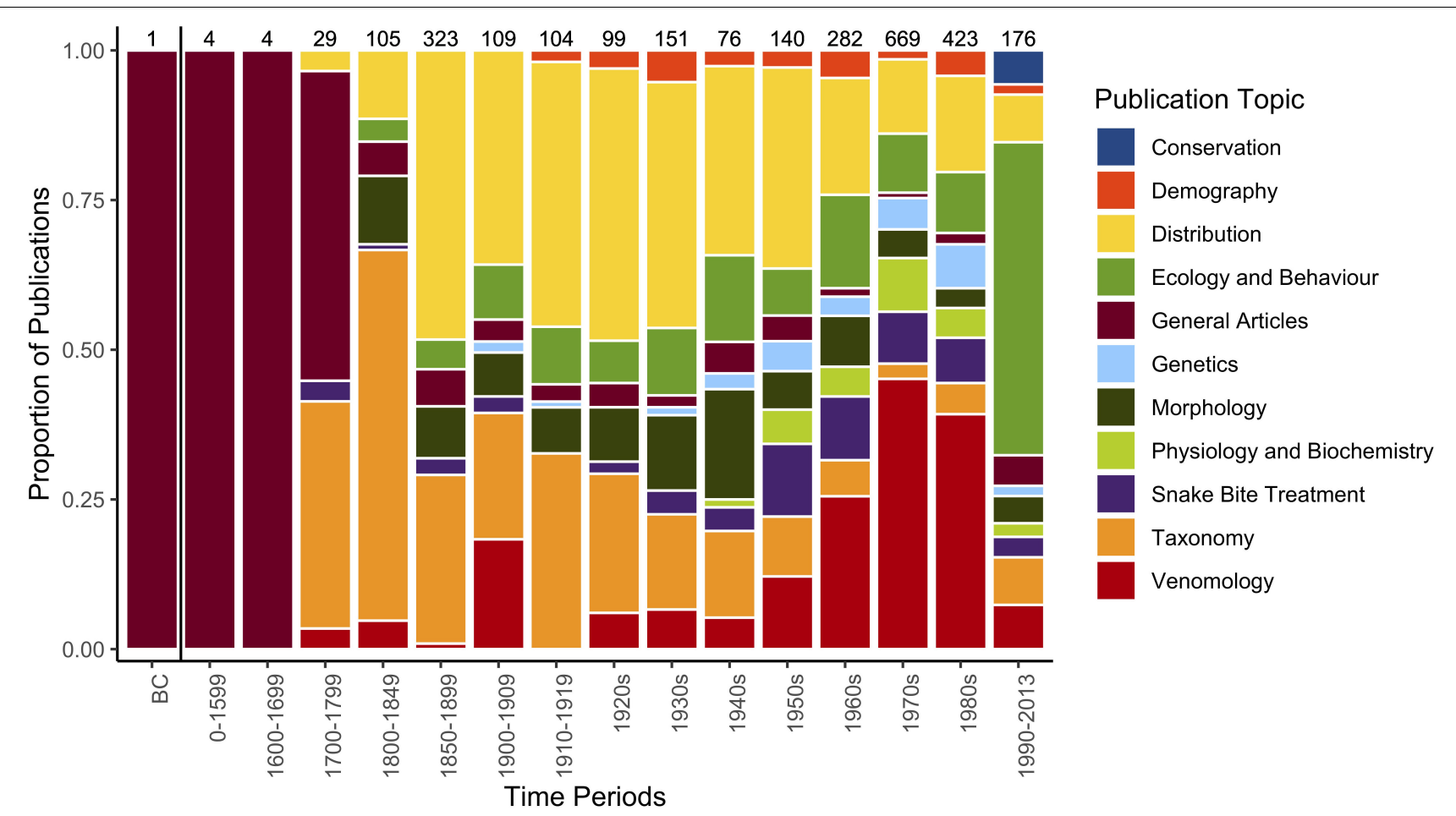

FIGURE 1 | Barplot showing the trend in number of publications focusing on marine snakes including sea snakes and sea kraits over time. Popular and semi-popular articles solely on methods are excluded. 'Ecology' includes natural history, trophic relationships, predators, parasites and relationship to the physical environment. 'Morphology' includes coloration. Numbers above bars represent publications during that time period. Figure recreated from Heatwole (2015) with permission. Data for articles prior to the 1980s were extracted from Culotta and Pickwell (1993) and composed of publications that mentioned sea snakes in any way, even if most of the article was on other taxa. Data from 1990 to 2013 are based on Heatwole (2015), who searched for articles that specifically focused on sea snakes, thereby lowering the number of publications.

status that may or may not be appropriate and which impacts the rigor of risk-assessments and regional policy regulating anthropogenic activities. Whilst systematic sampling is the most reliable way of filling these gaps, achieving adequate spatiotemporal replication over large marine geographic areas is logistically impractical. Hence, there is a need for alternative and cross-disciplinary methods to delimit species' distributions and evaluate interactions with threatening processes. Future research should consider a combination of genetic, field survey, and spatial modeling techniques to understanding the true geographic distributions and boundaries of species. Additionally, future researchers can greatly benefit from working alongside, and collating occurrence records from stakeholders, communities, and industry partners (e.g., remote indigenous communities, marine park managers, fishers) that frequently encounter marine snakes in remote locations from where distributional data is lacking.

\section{How far do marine snakes disperse and what are their habitat associations?}

Current understanding of the movement and habitat-use of a majority of species is based on early observational records for hydrophiine species (e.g., Heatwole, 1999). Recent studies using molecular markers and spatial monitoring have found that some marine snakes have small home-ranges
(Burns and Heatwole, 1998; Brischoux et al., 2009b) with limited gene flow over evolutionary and potentially, ecological timescales between geographically adjacent populations (Lukoschek et al., 2007; Lukoschek and Shine, 2012). Others display weaker geographic structuring (Bech et al., 2016), but only a few species have been studied in detail. Similarly, the occurrence of previously classified reef-associated species found within inshore seagrass habitats highlights the lack of accurate information on habitat associations for a range of frequently studied, but also threatened species (e.g., A. foliosquama and A. apraefrontalis; D'Anastasi et al., 2016), and a lack of information for other vulnerable and data-deficient species (e.g., Hydrophis pacificus, $H$. donaldi, Parahydrophis mertoni; Elfes et al., 2013).

Knowing species-specific dispersal capacities, as well as spatio-temporal patterns in habitat-use can help determine the vulnerability of regional populations of marine snakes to threatening processes (Bonnet et al., 2009; Udyawer et al., 2016b). For example, reef-specific threats will likely affect both sexes and all age classes of highly reef-associated and siteattached species (e.g., Emydocephalus annulatus; Lukoschek and Shine, 2012), but will disproportionately affect other species that display sexually dimorphic seasonal movements (e.g., Aipysurus laevis; Lynch, 1999). Similarly, the use of terrestrial habitats by amphibious and estuarine snakes (e.g., Laticauda spp., Ephalophis greyae, Hydrelaps darwiniensis, Parahydrophis mertoni) is still 
TABLE 1 | Summary of the twenty questions proposed to direct future research on marine snakes.

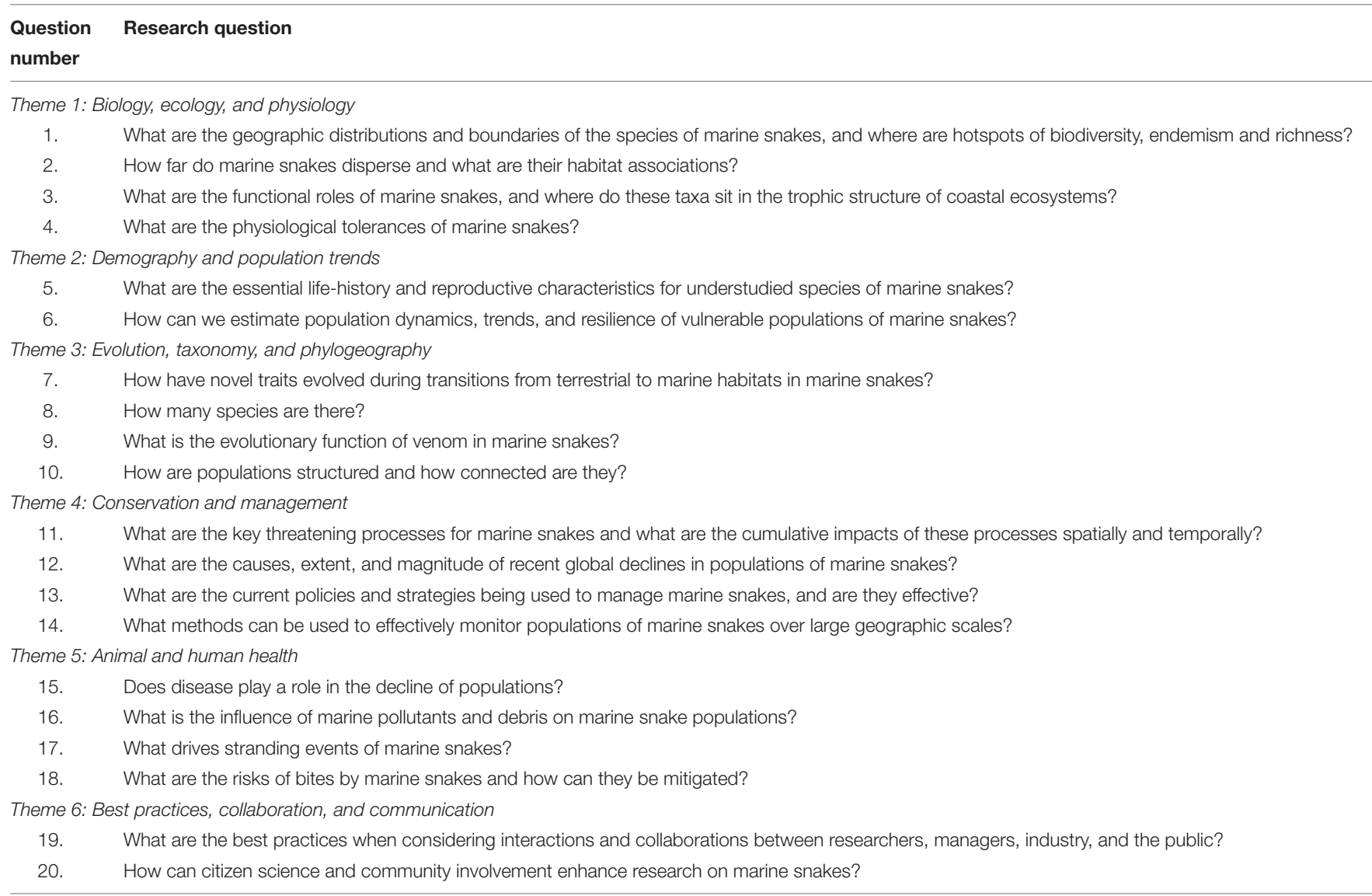

Questions are organized within six overarching themes and are in the order discussed in the manuscript, not by relative importance.

understudied. These species use terrestrial or tidal habitats as nesting and foraging sites (Bonnet et al., 2009; Liu et al., 2012). The influence of terrestrial micro-habitats on survival, growth, and reproduction is still not known. Ignoring the use of terrestrial habitats by these species risks misunderstanding their life histories and hampers mitigation of threatening processes in important terrestrial habitats (e.g., coastal development, mangrove die-backs).

Collecting fine-scale and long-term information on movements and habitat use in marine snakes is challenging, with a handful of radio and ultrasonic tracking techniques providing fundamental information on dispersal capacities and dive profiles of multiple species (Burns and Heatwole, 1998; Brischoux et al., 2007; Udyawer et al., 2016b). With the ongoing development of underwater tracking and sensor technology, future research on marine snakes can benefit from utilizing and adapting methodologies (e.g., acoustic tracking, accelerometry) and analytical techniques (e.g., three-dimensional positioning, movement path reconstruction, state-space modeling) used to study movement ecology and habitat use in other marine animals. A better understanding of fine-scale use of habitat is required to understand metapopulation dynamics and design effective management strategies. Capacity for movement and the use of habitat are essential for understanding past fluctuations in populations, as well as ecological requirements and capacity for replenishment of marine snakes, which can inform current and future decisions for conservation and management (Bonnet et al., 2014; Udyawer et al., 2016a).

\section{What are the functional roles of marine snakes, and where do these taxa sit in the trophic structure of coastal ecosystems?}

Marine snakes are predators that occupy a range of habitats, including coral reefs, estuaries, seagrass beds, mudflats, and pelagic systems. Understanding ecosystem roles of marine snakes is an important step in identifying essential habitats and can help evaluate the consequences of the removal of snakes from ecosystems (Elfes et al., 2013). The low encounter rates and secretive nature of marine snakes is a major limiting factor in collecting accurate and long-term information on habitat-association and diet. As a consequence, the influence of marine snakes in the functioning of coastal ecosystems is currently lacking for a large proportion of data-deficient species and is still imprecise for other commonly encountered species.

Currently, we have a good understanding of the diet of many species of marine snakes based on analyses of stomach contents of true sea snakes (Glodek and Voris, 1982; Voris and Voris, 1983), sea kraits (Brischoux et al., 2009c; Tabata et al., 2017), acrochordid (Voris and Glodek, 1980), and homalopsid snakes 
(Voris and Murphy, 2002). Some species are known to have extremely specialized diets (e.g., Fish egg specialists; Voris, 1966; Sanders et al., 2012). Although diets of marine snakes are welldocumented, we have rudimentary information on where these snake taxa occur in the trophic structure of their respective habitats, and the degree of dietary specialization across life stages and spatial distributions (Briand et al., 2016).

Understanding dietary specialization and trophic plasticity in marine snakes can help assess how populations may react to changes in the quality of habitats and in prey populations and, in turn, how declines in snake populations may affect the wider ecosystem (Reed et al., 2002; Brischoux et al., 2009a). Development and refinement of new techniques in this field have enabled the examination of dietary composition (e.g., dietary genetic sequencing; Goiran et al., 2013) and trophic position (e.g., stable isotopes; Brischoux et al., 2011) in more detail. These techniques should be utilized in future research with an aim of understanding the trophic plasticity of species, and how that shifts across habitats, and with ontogeny.

\section{What are the physiological tolerances of marine snakes?}

Recently, marine snakes have been reported from localities (e.g., Russia: Kharin, 2009; South Korea: Park et al., 2017) and depths that have sea temperatures lower than those previously considered limiting. Currently, there is insufficient information to assess if these occurrences represent vagrants, peripheral populations that have evolutionarily adjusted to cooler conditions, or newly established populations as a consequence of warming waters (Heatwole et al., 2016). Similarly, very little is known about how warming oceanic conditions may influence reproductive success and the prevalence of disease in marinesnake populations.

Contrary to long-held assumptions, true sea snakes and sea kraits do not drink seawater and dehydrate when they are not able to drink fresh water (Lillywhite et al., 2008, 2012, 2014a,b). Marine snakes have relatively high levels of body water, dehydrate slowly in seawater, and have variable sensitivity to dehydration (Lillywhite et al., 2014a,b). Some species have been reported to not drink fresh water even when dehydrated to deficits of body mass approaching 30\% (Lillywhite et al., 2015). Although none of the investigated species drink seawater, data from previous work suggest some species can survive without drinking fresh water for extended periods (Lillywhite et al., 2014b). Nevertheless, the requirement of freshwater has been shown to potentially restrict the distribution and seaward migrations of some species of coastal and estuarine marine snakes (Lillywhite and Ellis, 1994, Lillywhite and Ellis, 2018; Udyawer et al., 2016a). Understanding freshwater requirements and physiological tolerances to dehydration can provide critical information on how pelagic and coastal populations are influenced by the flow regimes of freshwater. Future research should endeavor to establish species-specific physiological tolerances to important environmental conditions (i.e., water temperature, freshwater flow regimes) using experimental and field-observational studies, as well as undertake longitudinal studies alongside long-term environmental monitoring to better understand how future environmental conditions may influence population health.

\section{Theme 2: Demography and Population Trends}

\section{What are the essential life-history and reproductive characteristics for understudied species of marine snakes?}

There is a need to gather accurate demographic information for a large number of species. Currently, limited demographic information has been collected for marine snakes commonly encountered in trawls (e.g., Fry et al., 2001; Ward, 2001; Wassenberg et al., 2001), and significant gaps exist for species of conservation concern (e.g., A. apraefrontalis, A. foliosquama, and $A$. fuscus). The International Union for the Conservation of Nature (IUCN) Red List database currently presents information on the habitat and ecology of most marine snakes ${ }^{1}$; however, these data typically refer to the general biology of the larger taxa, rather than to traits of individual species.

Estimation of fundamental species-specific demographic traits often involve destructive techniques that are not suitable for rare or threatened species. Techniques for aging individuals still require further research. Validation of standardized vertebral counts have only been conducted on two species (Hydrophis curtus and Hydrophis elegans; Ward, 2001). Such data are necessary for identifying the vulnerability of different life stages (e.g., juveniles or gravid females) to threatening processes and are crucial for assessing the risk of extinction (Zhou et al., 2012).

Currently, only a small number of studies have investigated age at sexual maturation, maximum age, and number of offspring (e.g., Lemen and Voris, 1981; Burns and Heatwole, 2000; Fry et al., 2001; Masunaga and Ota, 2003). Although the number of individuals in clutches/litters and the sizes of offspring are known for many marine snakes, how changes in environmental factors such as temperature and habitat quality affect reproductive biology and fecundity is still largely unknown. Often, maturity and the frequency of breeding are inferred indirectly from the proportion of reproductive individuals, or estimated from closely related species; however, eco-physiological constraints on maturity, spermatogenesis, vitellogenesis, pregnancy, oviposition, and incubation have not been assessed. Future studies should consider building on existing long-term monitoring to establish longitudinal and eco-physiological datasets, as well as to develop non-lethal techniques (e.g., hormonal analysis of blood, near infrared spectroscopy, radiocarbon dating) for assessing demographic traits and estimating mortality.

\section{How can we estimate population dynamics, trends, and resilience of vulnerable populations of marine snakes?}

There is also a lack of baseline information needed to assess resilience of marine-snake populations to chronic or episodic changes in mortality rates. Consistent monitoring

\footnotetext{
${ }^{1}$ www.iucnredlist.org
} 
using standardized methods is required to determine longterm trends in populations and the relative influence of anthropogenic pressures and environmental variability (e.g., marine heatwaves, drought, cyclones and storms, mangrove dieoffs, pollution, and coastal development). Mark-recapture studies are an effective method for understanding how populations are influenced by changes in environmental conditions (Voris, 1985; Bonnet, 2012). The few published studies of marinesnake assemblages that have measured species richness and relative abundance over a period of months and/or years show examples of stasis (Bonnet, 2012) as well as significant change over time (Guinea, 2013). Unfortunately, long-term markrecapture programs require considerable field effort and financial commitment. The identification and prioritization of vulnerable populations, and development of alternative survey techniques (e.g., video monitoring, environmental DNA) are required to ensure that limited resources are used effectively to collect data most likely to produce impactful management and conservationpolicy. Currently, there are few long-term monitoring studies of marine snakes (e.g., Bonnet, 2012; Goiran and Shine, 2013; Guinea, 2013). These are within Australian and New Caledonian waters, and there is a need to expand such work into other priority regions including the Persian Gulf and southern and southeastern Asia.

Understanding adaptation can also help assess the resilience of species to ecological challenges and opportunities. For example, species in the genus Hydrophis are the most rapidly speciating reptiles known to date (Lee et al., 2016). This group also shows high levels of morphological diversity and convergence, indicating a propensity for rapid adaptation in response to ecological challenges and opportunities. To better understand rapid evolution in marine snakes, future studies should investigate which and what types of genes and mutations are involved in adaptive shifts, and how demographic factors promote or constrain adaptive shifts. These investigations will inform major questions in evolution and are relevant to the conservation of biodiversity.

\section{Theme 3: Evolution, Taxonomy, and Phylogeography}

\section{How have novel traits evolved during transitions from terrestrial to marine habitats in marine snakes?}

Marine snakes are highly adapted to aquatic life (Heatwole, 1978) and evolved a suite of novel traits in response to marine habitats including sensory and mating systems, respiratory adaptations, venom, and locomotion. Unlike most other secondarily marine vertebrates, many marine snakes have close living relatives on land (Figure 2). True sea snakes and sea kraits, shared a common ancestor with the Australasian terrestrial elapids (i.e., taipans, death adders, tiger snakes) as recently as 20 million years ago (Sanders et al., 2008, 2010). Marine snakes also contain species that rely both on aquatic and terrestrial habitats, and that are semi-aquatic to fully-aquatic species (i.e., Ephalophis greyae, Parahydrophis mertoni, Hydrelaps darwiniensis). This provides a comparative framework to explore pathways of evolutionary change and past ecological transitions (Murphy, 2012).
Marine snakes can provide an insight into how sensory systems have shifted in response to marine environments. For example, vision, chemoreception, and hearing are important senses for terrestrial snakes, but these stimuli have different characteristics underwater, thus altering the selective pressures on sensory systems (Crowe-Riddell et al., 2016). Other sensory organs might compensate for reduced sensory cues in aquatic environments. Indeed, scale sensilla has been hypothesized to be more elaborate in some marine snakes than in their terrestrial counterparts (Figure 3; Crowe-Riddell et al., 2016). There are many unanswered questions regarding the sensory biology of marine snakes which should be a focus of future research. These include understanding how species recognize potential prey, predators, or mates, and how anthropogenic activities and changing environmental conditions may affect sensory cues and systems. Finally, an underexplored avenue of research is the convergent evolution of sensory systems in marine snakes with other aquatic vertebrates, such as a hydrodynamic or 'lateral line' sense (Westhoff et al., 2005; Crowe-Riddell et al., 2016) and cutaneous photoreception (Zimmerman and Heatwole, 1990).

\section{How many species are there?}

Although a basic question, understanding the true diversity of marine snakes is extremely important in defining the ecology and functional roles of this group. Currently, inconsistent practices are used to describe reptilian and amphibian lineages. We suggest setting a standard suite of markers and morphological traits to define species diversity in marine snakes that will maintain consistency across phylogenetic and population genetic studies. A review of current classification schemes is needed to identify suitable species-level divergence thresholds by comparing: (i) intraspecific divergence between populations of putative species and (ii) interspecific divergence among sister taxa using modeling approaches.

Quantifying the true diversity of marine snakes has been stymied by cryptic lineages and limited collection and genetic sampling. Ongoing fieldwork and integrated assessment of genetic and morphological data indicate that many widespread marine snake 'species' include multiple cryptic species, each with narrow distributions (Ukuwela et al., 2013; Sanders et al., 2014; Lukoschek, 2018a). Additionally, hybridization between closely related species with overlapping ranges may affect the true diversity of marine snakes (Sanders et al., 2014; Lukoschek, 2018b). Sparse sampling in many regions (e.g., Northwestern Australia, Philippine Islands, New Guinea, Indonesia) means that, in addition to new cryptic species, the discovery of completely novel species is also highly likely. Based on preliminary molecular studies conducted by Sanders colleagues an estimated 20 additional hydrophiine species remain to be discovered, increasing global marine snake diversity by at least $\sim 30 \%$.

\section{What is the evolutionary function of venom in marine snakes?}

Sea snakes and sea kraits have convergently evolved streamlined venoms that are reflective of their dietary specialization (i.e., fish; Fry et al., 2003). Due to this streamlining, antivenom developed 




to treat sea snake bites (e.g., CSL Sea Snake Antivenom, Commonwealth Serum Laboratories, Ltd., Australia) treats bites from the full range of Hydrophis and Aipysurus species, and as a consequence of the convergent biochemistry with sea kraits, also works to treat bites from Laticauda species (Chetty et al., 2004).

The evolution of venom and its toxicity arose through coevolution between snake species and their prey rather than as a defensive mechanisms (Barlow et al., 2009). Evidence for this in marine snakes lies in the fact that the few species that feed exclusively on fish eggs have nearly lost their venom apparatus, whereas those feeding on prey that can either escape or counterattack if not rapidly subdued, have well-developed venom apparatus (Gopalakrishnakone and Kochva, 1990; Li et al., 2005). Furthermore, some highly venomous species are reluctant to bite defensively (e.g., sea kraits), and in most species defensive bites often are dry (i.e., little or no venom delivered; Heatwole, 1975).

A full understanding of the role of venom in the biology of marine snakes must also consider co-evolutionary responses of prey. In New Guinea, eels (Gymnothorax hepaticus and G. undulatus) syntopic with Laticauda colubrina, a sea krait that preys nearly exclusively on eels, were highly resistant to venom. By contrast, eels found in adjacent habitats (Gorgasia maculata and Heteroconger hassi) or in the Atlantic (Gymnothorax moringa and Anguilla rostrata), where sea kraits have never occurred (Lillywhite et al., 2018), were less resistant
(Heatwole and Poran, 1995). The degree of resistance to sea krait venom was correlated with the extent of eels' contact with sea kraits, rather than with taxonomical differences (Heatwole and Powell, 1998).

We have a preliminary understanding of the effect of venoms (Zimmerman K.D. et al., 1992) and specific components of venoms (Zimmerman et al., 1993) of true sea snakes on various species of fish, but much more needs to be done before the mechanism of the action of venoms, or how venoms evolved, is fully known. For example, little is currently known about the role, if any, of the nephrotoxic component of marine snakes' venom. Aipysurus laevis produces proliferative glomerulonephritis and even death in mice well after victims have recovered from other effects of low doses (Zimmerman S.E. et al., 1992). This may be of medical importance to human victims who have recovered from bites from marine snakes via treatment with antivenom or by other means, as they may be susceptible to kidney failure at a later time, and is an important topic for future research.

\section{How are populations structured and how connected are they?}

Population genetic structure has been studied in few of the currently recognized species of marine snake, with a bias toward the true sea snakes (e.g., Lukoschek et al., 2011; Sheehy et al., 


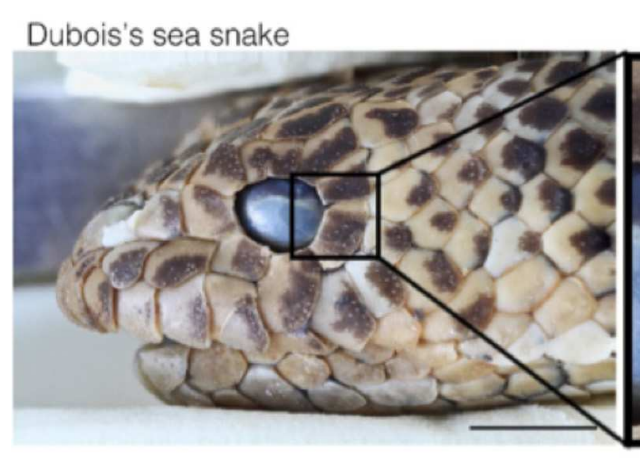

Brown snake

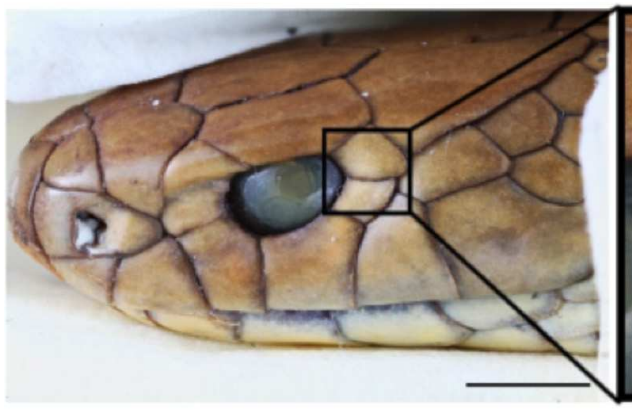

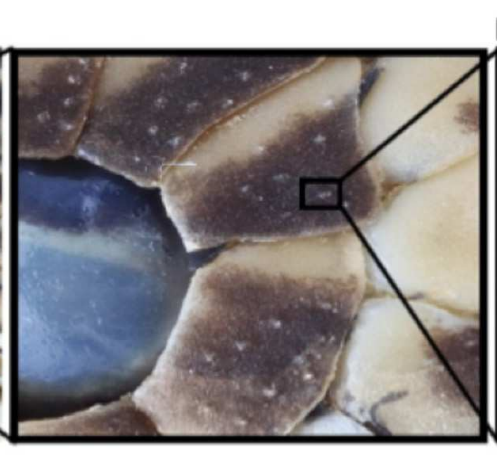

Marine



Terrestrial

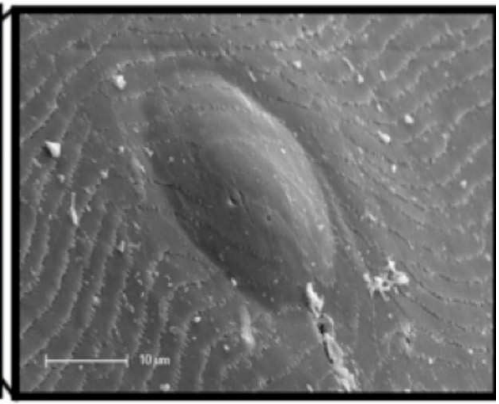

FIGURE 3 | Comparison of small scale organs, termed 'scale sensilla,' in fully-marine Aipysurus duboisii (top) and a close terrestrial relative Pseudonaja textilis (bottom). Scale sensilla in many aquatic species are more protruding and have a higher overall coverage than in terrestrial elapids. Modified with permission from Crowe-Riddell et al. (2016).

2012; Ukuwela et al., 2014; Lukoschek, 2018a). A combination of molecular markers and spatial monitoring reveal that some species exhibit limited movement and gene flow between geographically close populations (Lukoschek and Shine, 2012). Previous molecular studies have used datasets comprised of few $(<15)$ independent genetic markers such as mitochondrial DNA or microsatellites to assess connectivity between populations. Research could be improved through use of genetic data with higher resolution (i.e., single nucleotide polymorphisms) to investigate connectivity of populations on more recent ecological time scales.

A better understanding of connectivity and metapopulation dynamics can help define the geographic and temporal scales at which depleted populations could be replenished through migration from adjacent healthy populations. Additionally, understanding intraspecific genetic connectivity through comparative phylogeography is important for identifying hotspots of evolutionary potential (e.g., coastal Western Australia; Lukoschek, 2018a), which can assist decisions about conservation and management (e.g., determining boundaries for marine protected areas). The management of stocks requires knowledge of population structure, including effective population size and degree of connectivity among populations. This is particularly important for vulnerable and data-deficient species, which are subject to incidental mortality and sub-lethal effects from multiple stressors.

While research in restricted locations and focusing on finescale genetic variation are logistically easier to manage, they have limited applicability to decision-making at managementrelevant scales. As with other questions identified above, the scale and scope of the data collection needed to answer this research question is well-suited to a multi-institute, collaborative framework involving research and management organizations alongside industries or communities that encounter marine snakes (i.e., commercial or artisanal fisheries). Future research addressing this question should utilize phylogeographic techniques incorporating information from long-term surveys and species-level dispersal capacities measured using telemetry to gain an accurate understanding of marine snake populations at management-relevant temporal and spatial scales.

\section{Theme 4: Conservation and Management}

\section{What are the key threatening processes for} marine snakes and what are the cumulative impacts of these processes spatially and temporally?

While the key threatening processes that impact marine snakes are broadly acknowledged (e.g., targeted and incidental fishing, declining water quality, habitat loss, coastal development, disease, climate change), the specific nature, magnitude, and scale of these threats remains unquantified. Given the severity of declines and level of data deficiency in marine snakes, there is a need for a structured approach that characterizes threats, impacts, and mitigation strategies, and identifies gaps in knowledge. A systematic review of threats and impacts on marine snakes is urgently needed as a foundation for 
guiding future research and countering threats. Ideally the structure of such a review would align with domestic and international statutory processes (e.g., Key Threatening Process nomination criteria and Strategic Assessments under Australia's Environmental Protection and Biodiversity Conservation Act 1999) to maximize the utility of the process for managers and policy makers.

Further study is also needed to determine the impact of known threatening anthropogenic activity currently affecting vulnerable populations of marine snakes (Figure 4). For example, little is known about the true level marine snake mortality associated with fishing activity (Elfes et al., 2013). High rates of incidental by-catch and post-release mortality (up to 40\%) occur in some fisheries (e.g., demersal bottom trawling), however the effects on population health is largely unknown. Targeted harvest rates, and the reliance of fishers on income derived from marine snakes, as a low value by-catch species, is poorly understood (Lobo et al., 2010; Van Cao et al., 2014). Moreover, opportunistic targeting of rare, but high value species may be driving populations and species to extinction (Branch et al., 2013). This is of particular concern in increasingly unprofitable fisheries in southern and south-eastern Asia (Lobo et al., 2010). In the Gulf of Thailand, marine snakes are now a major commercial bycatch in squid fisheries retained due to their high abundance (Van Cao et al., 2014). Retention and sale of bycatch is currently an important subsidy to keep declining fisheries afloat, and marine snakes may constitute an important component of this subsidy in many fisheries in Asia. Currently little information is available for assessing how harvest is affecting local marine snake populations in these regions, and requires further research.

The influence of anthropogenic noise is another area that has received limited attention relative to marine snakes, but has well-documented negative impacts on other marine animals (Compton et al., 2008). Much like their terrestrial counterparts, marine snakes are likely to have a reduced sensitivity to air-borne sound due to their atympanic ear (Christensen et al., 2012), and instead are likely to detect vibrations in the substrate and pressure fluctuations associated with underwater sound (Westhoff et al., 2005). Preliminary tests conducted by Chapuis and Colleagues, on Hydrophis stokesii and Aipysurus laevis indicate hearing thresholds between 40 and $1000 \mathrm{~Hz}$, and like terrestrial snakes, peaks at low frequencies $(\sim 60 \mathrm{~Hz})$. This indicates marine snakes can hear pile driving noise $(400 \mathrm{~Hz})$, coastal shipping (100 to $1000 \mathrm{~Hz}$ ), and propeller noise (30 to $100 \mathrm{~Hz}$; Browse, 2013). Seismic surveys used in oil and gas exploration in coastal habitats operate at a frequency of less than $200 \mathrm{~Hz}$ and with a sound intensity and pressure of up to $255 \mathrm{~dB}$ re $1 \mu \mathrm{Pa}$ at $1 \mathrm{~m}$ (Swan et al., 1994). Having a single lung extending nearly the length of their body with inward opening valvular nostrils, marine snakes may have difficulty tolerating the continuous sound pressure from seismic arrays firing at three or four times per minute. With the current boom in offshore oil and gas exploration in marine snakes' biodiversity hotspots, research into the impact of seismic activity on marine snakes is critical. In addition to the two threats discussed here, future research should also seek to study impacts of other known threats to marine snakes including movement of maritime vessels, coastal development, degradation of habitats, and declines in prey populations.

\section{What are the causes, extent, and magnitude of recent global declines in populations of marine snakes?}

The vulnerability of marine-snake populations is exemplified by declines over decadal timescales in several regions (e.g., Great Barrier Reef, Australia: Lukoschek et al., 2007; New Caledonia: Goiran and Shine, 2013; Ashmore Reef, Western Australia: Guinea, 2013; Lukoschek et al., 2013). Of particular concern is that these declines have been reported in species with restricted ranges, in areas protected by marine reserves, and without readily identifiable causative factors. To prevent future catastrophic declines in populations of marine snakes, our limited understanding of these declines needs to be addressed. Studies examining temperature and rainfall at critical localities in combination with physiological studies, and monitoring population densities over time, are essential to address this issue. Research on marine snakes historically has been biased toward reefs and shoals where visibility is good and species are known to be abundant. A noticeable gap in information remains for coastal habitats, such as estuaries and lagoons, where individuals may be more difficult to observe. An initial step would be to identify how widespread declines might be across other habitats (e.g., estuarine and mangrove habitats) and geographic regions that are home to endemic species with small ranges.

Additionally, a research strategy for identifying candidate causative factors is needed. Future research should explore topics that include, but are not limited to: (i) changing environmental conditions caused by climate change, that might exceed physiological limits of some species (Lillywhite and Ellis, 1994; Heatwole et al., 2012), especially those specialized to conditions in specific areas; (ii), reduction in habitat quality and access to prey species; and/or (iii) increased mortality or decreased fecundity associated with diseases, high parasite-loads, or other physiological stressors.

\section{What are the current policies and strategies being used to manage marine snakes, and are they effective?}

Marine reserves and protected areas are among the key tools currently used to conserve and manage marine species and habitats. However, they are typically configured around key habitats and communities, and are rarely designed with the intention of conserving or managing specific marine taxa. However, marine reserves alone may be insufficient to address the causal mechanisms underpinning the declines of marine snakes. We need to determine the efficacy of current marine reserves alongside other spatial management (i.e., seasonal closures, multi-use zones), and regulation of human activity (e.g., management of bycatch or coastal and mining development). Identifying current management policies that are working to reduce threats to marine snakes, along with means for improving these policies, can effectively contribute to future management.

Incidental capture of marine snakes in trawl fisheries is a recurring threat throughout their global range. In Australian 

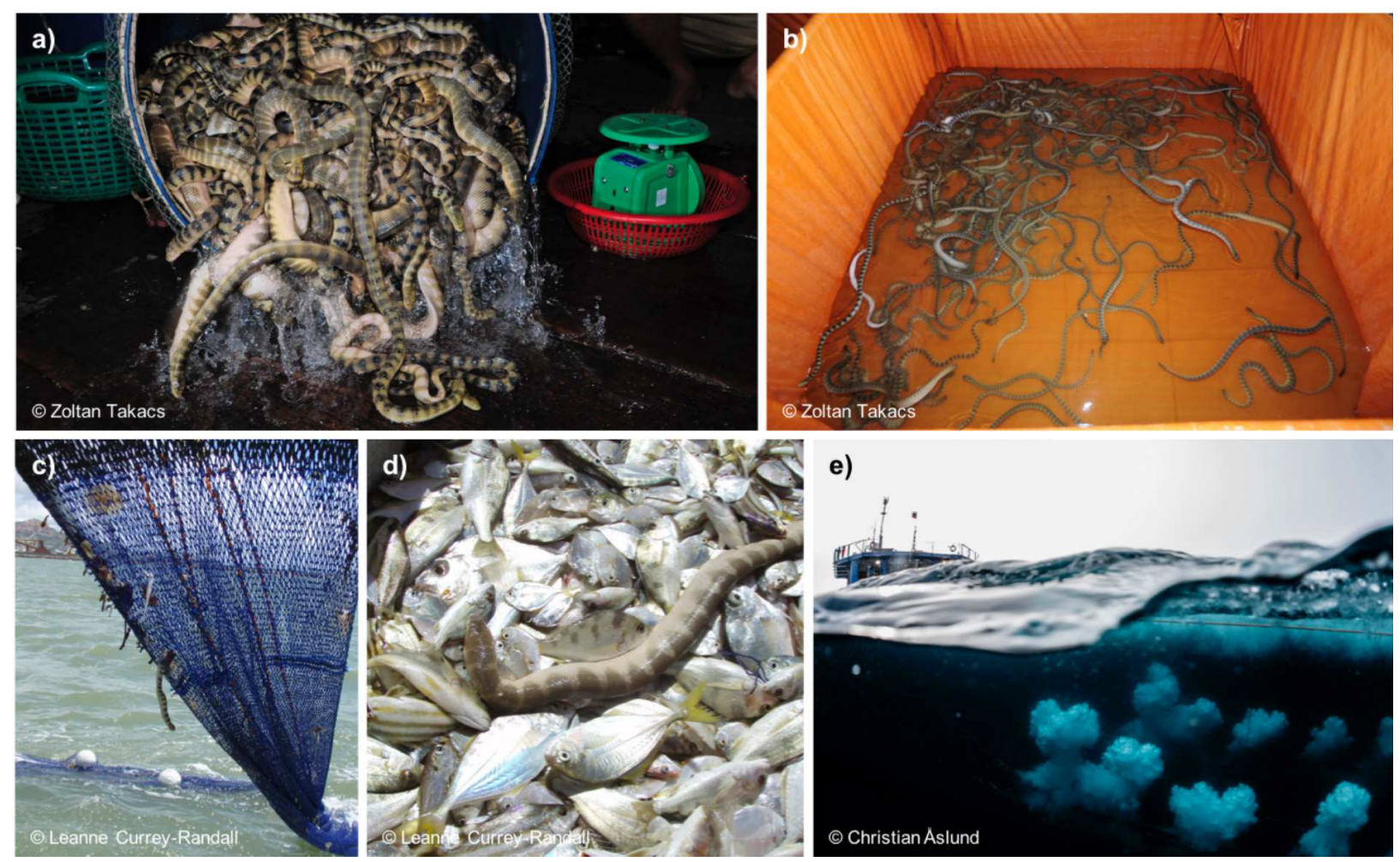

FIGURE 4 | Three known anthropogenic threatening processes on marine snakes; (a,b) targeted harvest of marine snakes in the Gulf of Thailand (Van Cao et al., 2014); (c,d) incidental capture in demersal trawl fisheries; and (e) influence of underwater seismic surveys and associated coastal development from offshore mining activities. Images provided with permission to use from Zoltan Takacs, Leanne Currey-Randall, and Christian Åslund.

waters, 1000s of true sea snakes are captured in tropical trawl fisheries each year. While great progress has been made by the introduction and mandatory use of bycatch reduction devices (BRDs) in Australian fisheries, such as turtle excluder devices that have reduced the incidental capture of sea turtles (Brewer et al., 2006), even with these devices capture of marine snakes remains high with reported mortality rates exceeding $40 \%$ or greater (Wassenberg et al., 2001). Other BRDs like 'Fisheye' and 'square meshes' have demonstrated partial effectiveness in allowing marine snakes to escape (Heales et al., 2008), with the former reducing sea snake bycatch by as much as $85 \%$ in Australia's Northern Prawn Fishery (Milton et al., 2009). In addition, BRDs reduce total mass within the net, and thus reduce mechanical damage to bycatch species. There is scope for future innovations in the design of nets or trawling methods to reduce and ultimately exclude marine snakes from trawl bycatch. Further research is required to evaluate the sublethal effects on snakes, particularly when caught multiple times, or held on board for extended periods (Heatwole, 1997). Unfortunately, implementation of BRDs in fisheries where marine snakes are major bycatch species (e.g., India, Bangladesh, Philippines, Thailand, Indonesia) may be impractical due to the retention of snakes in these regions. Therefore, a combination of spatial closures and fishing restrictions within important coastal habitats may be more effective in those regions (Udyawer et al., 2016a).

\section{What methods can be used to effectively monitor populations of marine snakes over large geographic scales?}

Monitoring of marine snakes using standardized methods is key for assessing long-term trends in community composition, population structure, and the relative influence of natural and anthropogenic pressures. Direct survey methods, such as inwater, fishery, and remote-camera surveys can underestimate biodiversity because of patchy and aggregated distributions over large and small spatial scales, resulting in variable rates of detection (Lukoschek et al., 2007; Udyawer et al., 2014). Detectability further varies with activity levels, tide, turbidity, and wave-height (Udyawer et al., 2015). Given the vast areas to be surveyed for marine snakes and the challenges associated with direct-survey techniques, an innovative approach is required.

Molecular techniques may offer a solution to some of the issues associated with sampling marine snakes. Environmental DNA (eDNA) is DNA shed by organisms and is temporarily retained in the environment through media such as soil and water (Ficetola et al., 2008). Studies of fish biodiversity have shown that eDNA can identify comparable or higher species diversity compared to direct-survey methods (Boussarie et al., 2018), and is likely superior in detecting rare and cryptic species (Jerde et al., 2011; Simpfendorfer et al., 2016), an issue highlighted in the present study. Moreover, eDNA samples can be collected, with relative ease, over vast geographic scales through 
collaboration with stakeholders such as fishers, governmental agencies (fisheries and wildlife management departments), universities, museums, and communities, due to the simplicity of sampling methods, e.g., use of a small portable pump (see Simpfendorfer et al., 2016).

Although eDNA may offer potential for monitoring marine biodiversity more effectively and with less effort, compared to direct approaches, considerable research is still required to develop techniques and standards that apply within the context of marine snakes (Hansen et al., 2018). Development of methods assessing the utility of eDNA as a broad-scale means for surveying marine snakes is required. Whilst the development of eDNA methods for any assemblage is a challenging undertaking (Hansen et al., 2018), the leap forward in capacity to monitor the biodiversity of marine snakes likely justifies the investment.

\section{Theme 5: Animal and Human Health 15. Does disease play a role in the decline of populations?}

Precipitous declines in marine snakes' populations within marine protected areas remain unexplained (Goiran and Shine, 2013; Lukoschek et al., 2013). One hypothesis for these declines is increased morbidity and/or mortality associated with diseases or high loads of parasites. Although diseases such as localized neoplasia and leukemia along with heavy parasite loads have been recorded from stranded marine snakes (Figure 5; Gillett et al., 2014), almost nothing is known about the prevalence of diseases and mortality rates in the wild. Increasing reports of deceased Emydocephalus annulatus within protected lagoons in New Caledonia, with no obvious cause of death have highlighted the need to understand if disease is playing a part in increased mortality in that region (Shine, personal observation). Additionally, understanding susceptibility to disease and its prevalence and spread in marine snakes as a consequence of rising sea-surface temperatures is urgently required (Harvell et al., 2002). The standard procedures in physical assessment of stranded marine snakes developed by Gillett et al. (2017) should be used in future research and monitoring programs to build a baseline understanding of the types and prevalence of diseases and the susceptibility of marine snakes to them. This information is vital for understanding the environmental correlates of the incidence of disease and can be used to model the potential for the spread of disease under future environmental conditions.

\section{What is the influence of marine pollutants and debris on marine snake populations?}

Marine snakes may act as bioindicators of marine health (Brischoux et al., 2009a), and as predators, they have the capacity to ingest pollutants and heavy metals accumulated within lower trophic species. Persistent organic pollutants can act as carcinogens and mutagens, and through ingestion, may accumulate within the fat, blood, liver, and kidneys of individuals (Rezaie-Atagholipour et al., 2012; Heydari Sereshk and Riyahi Bakhtiari, 2015). Multiple sea snakes from a populated region of southeastern Queensland, Australia, have recently been diagnosed with neoplasia of the pancreas, liver, and kidney, which are suspected of having a toxogenic or viral etiology
(Gillett et al., 2017) (Figure 5). Similarly, high concentrations of trace heavy metals have been recorded in sea snakes found near river-mouths and coastal habitats of New Caledonia, associated with high rates of pollution and run-off from mining activities (Goiran et al., 2017). Marine snakes co-inhabit areas of high fish stocks harvested for human consumption, and as such, the reporting of neoplasia and high contamination levels by Gillett et al. (2017) and Goiran et al. (2017) may have significant implications for human health.

In recent years, there have been increasing reports of mortality in sea snakes caused by marine debris, plastics, and derelict fishing gear in coastal habitats around the world (e.g., Udyawer et al., 2013); there is little understanding of how common these events are and how they influence the health of populations. Future research should aim to quantify bioaccumulation of contaminants in marine snakes and identify environmental pollutants that threaten regional populations. Similarly, there is a need to better understand mortality and sub-lethal effects on marine snakes from micro-plastics and marine debris.

\section{What drives stranding events of marine snakes?}

Anecdotal strandings of marine snakes are regularly observed and a few thorough investigations into the state of beach-washed snakes have been conducted (Gillett, 2017). Stranded animals can provide insight into disease, toxicology/bioaccumulation, injury, and the impact of reduced habitat and food reserves. Given the limited knowledge about many populations of marine snakes, stranded individuals may provide valuable information on distribution, health, and local and global threats. Future study in quantifying stranding rates and identifying causative factors are needed. Moreover, a streamlined process for reporting and collating data on strandings should be developed, for example, through integration with existing local programs that record marine strandings (e.g., Eye on the Reef ${ }^{2}$ ).

\section{What are the risks of bites by marine snakes and how can they be mitigated?}

Envenomation by marine snakes is a major issue in some regions (Alirol et al., 2010), but trivial in others (Heatwole, 1975). For example, snakebites are rare in New Caledonia despite the abundance both of sea kraits and true sea snakes (Heatwole, 1999), whereas incidences are higher in coastal regions of Sri Lanka, primarily attributed to one species (Hydrophis schistosus; Senanayake et al., 2005). Bites by marine snakes are an occupational hazard for fisheries-related work in tropical coastal waters of Australia and South East Asia. Currently the only antidote used for envenomation by marine snakes in most regions is the Australian CSL sea-snake antivenom, which often is not available, extremely expensive locally, and requires extreme care in transport and storage (Tan et al., 2015). Therefore, mitigating the risk of bites in these regions calls for effective preventative measures. Mitigation strategies can include educating fishers or those in contact with snakes about safe handling practices to prevent bites, or managing human-snake interactions using

${ }^{2}$ www.gbrmpa.gov.au/managing-the-reef/how-the-reefs-managed/eye-on-thereef 


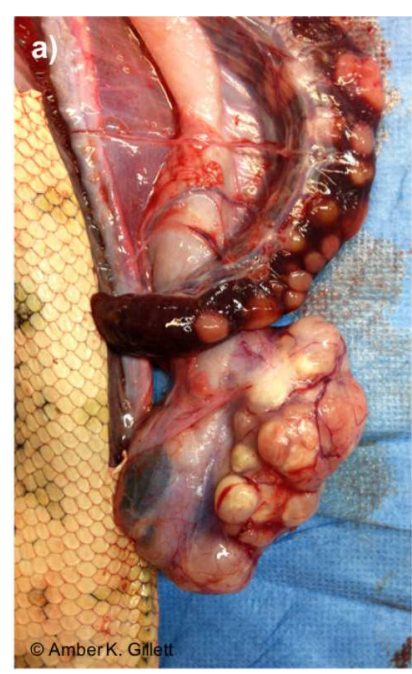

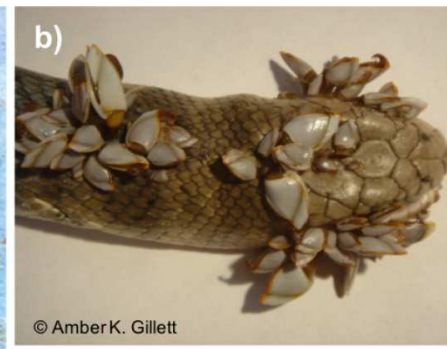

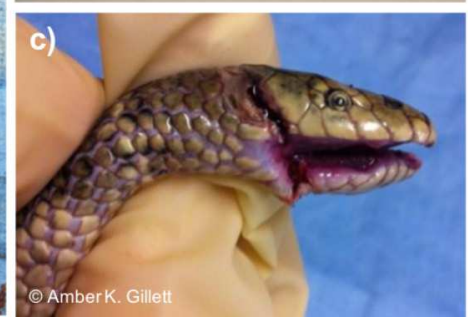

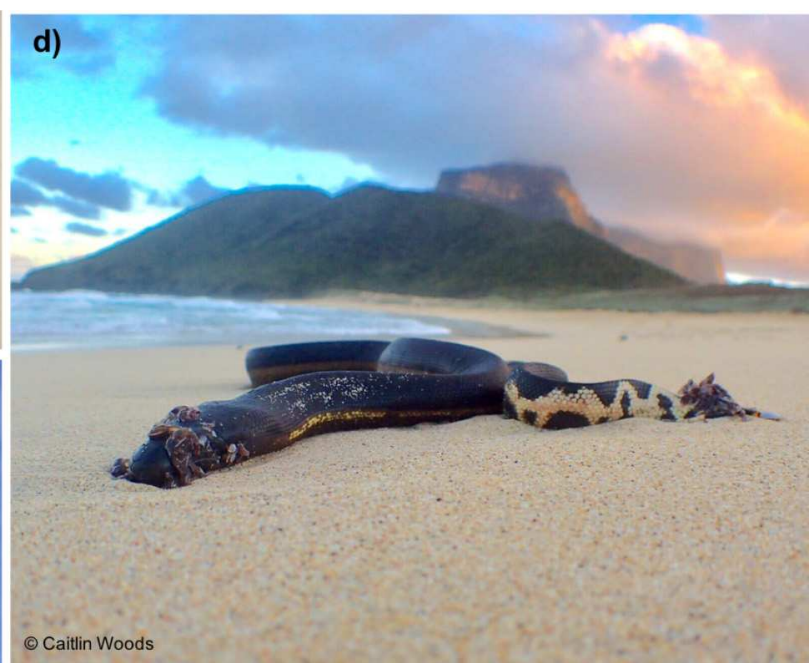

FIGURE 5 | Disease and strandings of marine snakes; (a) stranded Hydrophis elegans found with neoplastic masses through the liver and splenopancreas consistent with adenocarcinoma; (b) beach-washed H. major that presented with seizures and head twitching, and heavily parasitized with Lepas ansifera barnacles; (c) linear wound to the head of a H. elegans from presumed boat strike; and (d) stranded pelagic sea snake (H. platurus) with heavy biofouling. Images provided with permission to use from Amber K. Gillett and Caitlin Woods.

spatial or seasonal warning systems. Information from areas where bites are common would add greatly to our understanding of the determinants of risk, and of potential pre-emptive counter measures.

\section{Theme 6: Best Practices, Collaboration, and Communication}

\section{What are the best practices when considering interactions and collaborations between researchers, managers, industry, and the public?}

As highlighted by previous questions, there is a need for increased collection of data, across multiple fields, on marine snakes throughout their global range. However, in comparison to many other target species, marine snakes are relatively difficult to gather in sufficient numbers for robust analyses. As such, samples, especially in the case of studies where destructive sampling is unavoidable, should make the best use of the materials gathered. Currently, there is a great deal of cooperation and collaboration among researchers within regions; however, there is potential to improve collaborations among researchers, industry, and managers across regions.

There is potential for a central data bank that can be accessed by multiple researchers and managers, where whole specimens, samples (e.g., blood, tissue) or data can be shared across institutions. This may take the form of a physical location where samples are kept (e.g., Ian Potter BioBank, Museums), or a better option may be a virtual bank/collaborative network where specimens or data are made available to researchers on an asneeds basis (e.g., Otlet ${ }^{3}$ ). Collaborative links with industries that interact with marine snakes may significantly enhance availability of samples and may be facilitated by expedited exemptions

${ }^{3}$ https://otlet.io and licensing for participants from industry. Together with collaborative infrastructure, there is also a need to establish standardized operating procedures for the collection and storage of data, and the handling, husbandry, and ethical treatment of animals, to ensure usability of samples and data across industry, research institutions, and governmental agencies.

\section{How can citizen science and community involvement enhance research on marine snakes?}

Given the variety of people likely to have contact with marine snakes (e.g., offshore oil and gas industry, fishing industry, recreational divers/fishers, beach-goers) and potential hazards (e.g., envenomation), there is an opportunity to collect data and educate the public about this unique group of reptiles. Collection of data from citizen scientists and beach-goers can be as simple as reporting stranded marine snakes (Gillett, 2017), through to more involved structured and repeated sampling by volunteers. A good example of the latter is an ongoing monitoring program in New Caledonia conducted by Goiran colleagues, where citizen-scientist volunteers regularly participate in surveys and submit photographs of marine snakes within fringing reefs in close proximity to recreational beaches. To facilitate and foster interest from the public, development of an easyaccess, updated field guide in the form of a mobile application with photographs and the ability to record verified sightings would be extremely beneficial. Currently, similar systems exist for broad-scale reporting of biodiversity within Australia and globally (e.g., Redmap ${ }^{4}$, HerpMapper ${ }^{5}$, iNaturalist ${ }^{6}$ ); however, these systems can be developed further for applicability to marine snakes. Similarly, development of easy-to-use identification and

\footnotetext{
${ }^{4}$ www.redmap.org.au

${ }^{5}$ www.herpmapper.org

${ }^{6}$ www.inaturalist.org
} 
education kits for use by local fishers, indigenous communities, and tourists in remote areas may enhance the information-base and remove preconceived stigma associated with snakes in many regions and communities.

\section{CONCLUDING REMARKS}

With the increased interest from universities, conservation and management agencies, industry, and the public in understanding more about marine snakes, there is a strong drive to expand our knowledge about these remarkable reptiles. More than onethird of marine snake species currently assessed by the IUCN are classified as Data Deficient (Elfes et al., 2013), and other species remain undiscovered or undescribed. Despite large annual rates of harvesting marine snakes in many regions (Punay, 1975; Van Cao et al., 2014) (Figure 4), they rarely receive adequate protection from regional or national wildlife laws. For example, in spite of recorded declines in populations due to targeted harvests, there are no local laws to protect marine snakes in Vietnam (Van Cao et al., 2014). Similarly, in India only four of the 25 species of marine snake find a mention in the Indian Wildlife Protection Act, and that too in a section that confers them with little to no protection from increased fisheries interactions. Unfortunately, at present, sufficient species-specific population health, trends, and distributions are not available for most species of marine snake to support protections in many national and international conservation agreements [e.g., Convention in International Trade in Endangered Species of Wild Fauna and Flora (CITES), Convention on the Conservation

\section{REFERENCES}

Alirol, E., Sharma, S. K., Bawaskar, H. S., Kuch, U., and Chappuis, F. (2010). Snake bite in South Asia: a review. PLoS Negl. Trop. Dis. 4:e603. doi: 10.1371/journal. pntd.0000603

Barlow, A., Pook, C. E., Harrison, R. A., and Wüster, W. (2009). Coevolution of diet and prey-specific venom activity supports the role of selection in snake venom evolution. Proc. R. Soc. B 276, 2443-2449. doi: 10.1098/rspb.2009.0048

Bech, N., Foucart, T., Fauvel, T., Brischoux, F., Bouchon, D., and Bonnet, X. (2016). Phenotypic variation contrasts with genetic homogeneity across scattered sea snake colonies. J. Biogeogr. 43, 1573-1582. doi: 10.1111/jbi.12735

Bonnet, X. (2012). Long-term field study of sea kraits in New Caledonia: fundamental issues and conservation. Integr. Comp. Biol. 52, 281-295. doi: 10.1093/icb/ics069

Bonnet, X., Brischoux, F., Bonnet, C., Plichon, P., and Fauvel, T. (2014). Coastal nurseries and their importance for conservation of sea kraits. PLoS One 9:e90246. doi: 10.1371/journal.pone.0090246

Bonnet, X., Brischoux, F., Pearson, D., and Rivalan, P. (2009). Beach rock as a keystone habitat for amphibious sea snakes. Environ. Conserv. 36, 62-70. doi: 10.1017/S0376892909005451

Bonnet, X., Rasmussen, A., and Brischoux, F. (2016). "Sea snakes," in Reptile Ecology and Conservation: A Handbook of Techniques, ed. C. K. Dodd Jr. (Oxford: Oxford University Press), 154-167. doi: 10.1093/acprof:oso/ 9780198726135.003.0012

Boussarie, G., Bakker, J., Wangensteen, O. S., Mariani, S., Bonnin, L., Juhel, J.-B., et al. (2018). Environmental DNA illuminates the dark diversity of sharks. Sci. Adv. 4:eaa9661. doi: 10.1126/sciadv.aap9661

Branch, T. A., Lobo, A. S., and Purcell, S. W. (2013). Opportunistic exploitation: an overlooked pathway to extinction. Trends Ecol. Evol. 28, 409-413. doi: 10.1016/ j.tree.2013.03.003 of Migratory Species of Wild Animals (CMS); Elfes et al., 2013]. This highlights a critical need for future species-specific research to better understand the fundamental ecology of marine snakes, fill critical gaps in knowledge, implement effective regional management to set quotas to determine sustainable harvest, and manage coastal development in critical habitats for this unique group of marine reptiles.

The research and management questions presented here are by no means a comprehensive list, but are an initial step in identifying and filling key gaps in knowledge. These questions provide an opportunity to initiate cross disciplinary and multistakeholder collaborative projects, not only to advance our understanding of these animals, but to provide managementrelevant information to aid conservation.

\section{AUTHOR CONTRIBUTIONS}

VU conceived the study, conducted surveys, and led the writing of the manuscript. All co-authors participated in the survey, contributed significantly to the manuscript, and gave final approval for publication.

\section{FUNDING}

This project was supported by The Australian Government's National Environmental Science Program (NESP) Marine Biodiversity Hub, and is an output from Project A8 led by VU and MRH.

Brewer, D., Heales, D., Milton, D., Dell, Q., Fry, G., Venables, B., et al. (2006). The impact of turtle excluder devices and bycatch reduction devices on diverse tropical marine communities in Australia's northern prawn trawl fishery. Fish. Res. 81, 176-188. doi: 10.1016/j.fishres.2006. 07.009

Briand, M. J., Bonnet, X., Guillou, G., and Letourneur, Y. (2016). Complex food webs in highly diversified coral reefs: Insights from $\delta 13 \mathrm{C}$ and $\delta 15 \mathrm{~N}$ stable isotopes. Food Webs 8, 12-22. doi: 10.1016/j.fooweb.2016. 07.002

Brischoux, F., Bonnet, X., Cherel, Y., and Shine, R. (2011). Isotopic signatures, foraging habitats and trophic relationships between fish and seasnakes on the coral reefs of New Caledonia. Coral Reefs 30, 155-165. doi: 10.1007/s00338010-0680-8

Brischoux, F., Bonnet, X., Cook, T., and Shine, R. (2007). "Snakes at sea: diving performances of free-ranging sea kraits," in Proceedings of the 11th Annual Meeting on Health, Science and Technology, San Diego, CA.

Brischoux, F., Bonnet, X., and Legagneux, P. (2009a). Are sea snakes pertinent bioindicators for coral reefs? A comparison between species and sites. Mar. Biol. 156, 1985-1992. doi: 10.1007/s00227-009-1229-7

Brischoux, F., Bonnet, X., and Pinaud, D. (2009b). Fine scale site fidelity in sea kraits: implications for conservation. Biodiv. Conserv. 18, 2473-2481. doi: 10.1007/s10531-009-9602-x

Brischoux, F., Bonnet, X., and Shine, R. (2009c). Determinants of dietary specialization: a comparison of two sympatric species of sea snakes. Oikos 118, 145-151. doi: 10.1111/j.1600-0706.2008.17011.x

Browse, L. (2013). Dredging and Spoil Disposal Management Plan Darwin. Darwin, SA: INPEX.

Burns, G., and Heatwole, H. (1998). Home range and habitat use of the olive sea snake, Aipysurus laevis, on the Great Barrier Reef, Australia. J. Herpetol. 32, 350-358. doi: $10.2307 / 1565449$ 
Burns, G., and Heatwole, H. (2000). Growth, sexual dimorphism, and population biology of the olive sea snake, Aipysurus laevis, on the Great Barrier Reef of Australia. Amp. Rep. 21, 289-300. doi: 10.1163/156853800507480

Chetty, N., Du, A., Hodgson, W. C., Winkel, K., and Fry, B. G. (2004). The in vitro neuromuscular activity of Indo-Pacific sea-snake venoms: efficacy of two commercially available antivenoms. Toxicon 44, 193-200. doi: 10.1016/j. toxicon.2004.05.022

Christensen, C. B., Christensen-Dalsgaard, J., Brandt, C., and Madsen, P. T. (2012). Hearing with an atympanic ear: good vibration and poor soundpressure detection in the royal python, Python regius. J. Exp. Biol. 215, 331-342. doi: $10.1242 /$ jeb.062539

Compton, R., Goodwin, L., Handy, R., and Abbott, V. (2008). A critical examination of worldwide guidelines for minimising the disturbance to marine mammals during seismic surveys. Mar. Policy 32, 255-262. doi: 10.1016/j. marpol.2007.05.005

Crowe-Riddell, J. M., Snelling, E. P., Watson, A. P., Suh, A. K., Partridge, J. C., and Sanders, K. L. (2016). The evolution of scale sensilla in the transition from land to sea in elapid snakes. Open Biol. 6:160054. doi: 10.1098/rsob.160054

Culotta, W. A., and Pickwell, G. V. (1993). The Venomous Sea Snakes: A Comprehensive Bibliography. George Washington, VA: Krieger Pub Co.

D'Anastasi, B. R., van Herwerden, L., Hobbs, J. A., Simpfendorfer, C. A., and Lukoschek, V. (2016). New range and habitat records for threatened Australian sea snakes raise challenges for conservation. Biol. Conserv. 194, 66-70. doi: 10.1016/j.biocon.2015.11.032

Dunson, W. A. (1975). The Biology of Sea Snakes. Baltimor, MD: University Park Press.

Elfes, C. T., Livingstone, S. R., Lane, A., Lukoschek, V., Sanders, K., Courtney, A. J., et al. (2013). Fascinating and forgotten: the conservation status of marine elapid snakes. Herpetol. Conserv. Biol. 8, 37-52.

Ficetola, G. F., Miaud, C., Pompanon, F., and Taberlet, P. (2008). Species detection using environmental DNA from water samples. Biol. Lett. 4, 423-425. doi: $10.1098 / \mathrm{rsbl} .2008 .0118$

Fry, B. G., Wuster, W., Kini, R. M., Brusic, V., Khan, A., Venkataraman, D., et al. (2003). Molecular evolution and phylogeny of elapid snake venom three-finger toxins. J. Mol. Evol. 57, 110-129. doi: 10.1007/s00239-003-2461-2

Fry, G., Milton, D., and Wassenberg, T. (2001). The reproductive biology and diet of sea snake bycatch of prawn trawling in Northern Australia: characteristics important for assessing the impacts on populations. Pac. Conserv. Biol. 7, 55-73. doi: 10.1071/PC010055

Gillett, A. K. (2017). An investigation into the stranding of Australian sea snakes. Ph.D. thesis, The University of Queensland, St Lucia, QLD.

Gillett, A. K., Flint, M., and Mills, P. C. (2014). An antemortem guide for the assessment of stranded Australian sea snakes (Hydrophiinae). J. Zoo Wildl. Med. 45, 755-765. doi: 10.1638/2013-0265.1

Gillett, A. K., Ploeg, R., Flint, M., and Mills, P. C. (2017). Postmortem examination of Australian sea snakes (Hydrophiinae): anatomy and common pathologic conditions. J. Vet. Diagn. Invest. 29, 593-611. doi: 10.1177/10406387177 10056

Glodek, G. S., and Voris, H. K. (1982). Marine snake diets: prey composition, diversity and overlap. Copeia 1982, 661-666. doi: 10.2307/1444667

Goiran, C., Bustamante, P., and Shine, R. (2017). Industrial melanism in the sea snake Emydocephalus annulatus. Curr. Biol. 27, 2510.e2-2513.e2. doi: 10.1016/ j.cub.2017.06.073

Goiran, C., Dubey, S., and Shine, R. (2013). Effects of season, sex and body size on the feeding ecology of turtle-headed sea snakes (Emydocephalus annulatus) on IndoPacific inshore coral reefs. Coral Reefs 32, 527-538. doi: 10.1007/s00338012-1008-7

Goiran, C., and Shine, R. (2013). Decline in sea snake abundance on a protected coral reef system in the New Caledonian Lagoon. Coral Reefs 32, 281-284. doi: 10.1007/s00338-012-0977-x

Gopalakrishnakone, P., and Kochva, E. (1990). Venom glands and some associated muscles in sea snakes. J. Morphol. 205, 85-96. doi: 10.1002/jmor.105205 0109

Guinea, M. L. (2013). "Surveys of the sea snakes and sea turtles on reefs of the Sahul Shelf. Final Report 2012-2013," in Proceedings of the Monitoring Program for the Montara Well Release Timor Sea, Drysdale, VIC.

Hansen, B. K., Bekkevold, D., Clausen, L. W., and Nielsen, E. E. (2018). The sceptical optimist: challenges and perspectives for the application of environmental DNA in marine fisheries. Fish Fish. 19, 751-768. doi: 10.1111/ faf. 12286

Harvell, C. D., Mitchell, C. E., Ward, J. R., Altizer, S., Dobson, A. P., Ostfeld, R. S., et al. (2002). Climate warming and disease risks for terrestrial and marine biota. Science 296, 2158-2162. doi: 10.1126/science.1063699

Hays, G. C., Ferreira, L. C., Sequeira, A. M. M., Meekan, M. G., Duarte, C. M., Bailey, H., et al. (2016). Key questions in marine megafauna movement ecology. Trends Ecol. Evol. 31, 463-475. doi: 10.1016/j.tree.2016.02.015

Heales, D. S., Gregor, R., Wakeford, J., Wang, Y. G., Yarrow, J., and Milton, D. A. (2008). Tropical prawn trawl bycatch of fish and seasnakes reduced by Yarrow Fisheye Bycatch Reduction Device. Fish. Res. 89, 76-83. doi: 10.1016/j.fishres. 2007.09.002

Heatwole, H. (1975). Attacks by Sea Snakes on Divers. The Biology of Sea Snakes. Baltimore, MD: University Park Press, 503-516.

Heatwole, H. (1978). Adaptations of Marine Snakes: unusual physiological strategies have enabled some snakes to live in a saltwater environment. Am. Sci. 66, 594-604.

Heatwole, H. (1997). Marine snakes: are they a sustainable resource? Wildlife Soc. Bull. 25, 766-772.

Heatwole, H. (1999). Sea Snakes. Sydney, SA: University of New South Wales Press. Heatwole, H. (2015). Pristine wilderness to crippled ecosystems: a foray through more than half a century of herpetology. J. Herpetol. 49, 333-342. doi: 10.1670/ 14-144

Heatwole, H., Grech, A., and Marsh, H. (2017). Paleoclimatology, paleogeography, and the evolution and distribution of sea kraits (Serpentes; Elapidae; Laticauda). Herpetol. Monogr. 31, 1-17. doi: 10.1655/HERPMONOGRAPHS-D-16-00003

Heatwole, H., Grech, A., Monahan, J. F., King, S., and Marsh, H. (2012). Thermal biology of sea snakes and sea kraits. Integr. Comp. Biol. 52, 257-273. doi: $10.1093 / \mathrm{icb} / \mathrm{ics} 080$

Heatwole, H., Lillywhite, H., and Grech, A. (2016). Physiological, ecological, and behavioural correlates of the size of the geographic ranges of sea kraits (Laticauda; Elapidae, Serpentes): a critique. J. Sea Res. 115, 18-25. doi: 10.1016/ j.seares.2016.05.003

Heatwole, H., and Poran, N. S. (1995). Resistances of sympatric and allopatric eels to sea snake venoms. Copeia 1995, 136-147. doi: 10.2307/1446808

Heatwole, H., and Powell, J. (1998). Resistance of eels (Gymnothorax) to the venom of sea kraits (Laticauda colubrina): a test of coevolution. Toxicon 36, 619-625. doi: 10.1016/S0041-0101(97)00081-0

Heydari Sereshk, Z., and Riyahi Bakhtiari, A. (2015). Concentrations of trace elements in the kidney, liver, muscle, and skin of short sea snake (Lapemis curtus) from the Strait of Hormuz Persian Gulf. Environ. Sci. Pollut. Res. 22, 15781-15787. doi: 10.1007/s11356-015-4631-3

Jerde, C. L., Mahon, A. R., Chadderton, W. L., and Lodge, D. M. (2011). “Sightunseen" detection of rare aquatic species using environmental DNA. Conserv. Lett. 4, 150-157. doi: 10.1111/j.1755-263X.2010.00158.x

Kangas, M. I., Sporer, E. C., Hesp, S. A., Travaille, K. L., Brand-Gardner, S. J., Cavalli, P., et al. (2015a). Shark Bay Prawn Managed Fishery. Western Australian Marine Stewardship Council Report Series, No. 2. Perth, WA: Department of Fisheries, 294.

Kangas, M. I., Sporer, E. C., Hesp, S. A., Travaille, K. L., Moore, N., Cavalli, P., et al. (2015b). Exmouth Gulf Prawn Managed Fishery. Western Australian Marine Stewardship Council Report Series, No. 1. Perth, WA: Department of Fisheries, 273.

Kharin, V. E. (2009). Redescription of a Russian finding of the erabu sea krait Pseudolaticauda semifasciata (Reinwardt in Schlegel, 1837), with remarks about species composition of sea snakes (Serpentes: Laticaudidae, Hydrophiidae) in Russian and adjacent waters. Russ. J. Mar. Biol. 35, 8-14. doi: 10.1134/ s1063074009010027

Lee, M. S. Y., Sanders, K. L., King, B., and Palci, A. (2016). Diversification rates and phenotypic evolution in venomous snakes (Elapidae). R. Soc. Open Sci. 3:150277. doi: 10.1098/rsos.150277

Lemen, C. A., and Voris, H. K. (1981). A comparison of reproductive strategies among marine snakes. J. Anim. Ecol. 50, 89-101. doi: 10.2307/4033

Li, M., Fry, B. G., and Kini, R. M. (2005). Eggs-only diet: its implications for the toxin profile changes and ecology of the marbled sea snake (Aipysurus eydouxii). J. Mol. Evol. 60, 81-89. doi: 10.1007/s00239-004-0138-0

Lillywhite, H. B., Babonis, L. S., Sheehy, I. I. I., Coleman, M., and Tu, M. C. I. I. I. (2008). Sea snakes (Laticauda spp.) require fresh drinking water: implication 
for the distribution and persistence of populations. Physiol. Biochem. Zool. 81, 785-796. doi: 10.1086/588306

Lillywhite, H. B., Brischoux, F., Sheehy, C. M., and Pfaller, J. B. (2012). Dehydration and drinking responses in a pelagic sea snake. Integr. Comp. Biol. 52, 227-234. doi: $10.1093 / \mathrm{icb} / \mathrm{ics} 039$

Lillywhite, H. B., and Ellis, T. M. (1994). Ecophysiological aspects of the coastalestuarine distribution of Acrochordid snakes. Estuaries 17, 53-61. doi: 10.2307/ 1352334

Lillywhite, H. B., Heatwole, H., and Sheehy, C. M. III (2014a). Dehydration and drinking behavior of the marine file snake Acrochordus granulatus. Physiol. Biochem. Zool. 87, 46-55. doi: 10.1086/673375

Lillywhite, H. B., Heatwole, H., and Sheehy, C. M. (2015). Dehydration and drinking behavior in true sea snakes (Elapidae: Hydrophiinae: Hydrophiini). J. Zool. 296, 261-269. doi: 10.1111/jzo.12239

Lillywhite, H. B., Sheehy, C. M. III, Brischoux, F., and Grech, A. (2014b). Pelagic sea snakes dehydrate at sea. Proc. R. Soc. B 281:20140119. doi: 10.1098/rspb.2014. 0119

Lillywhite, H. B., Sheehy, C. M. III, Heatwole, H., Brischoux, F., and Steadman, D. W. (2018). Why are there no sea snakes in the Atlantic? BioScience 68, 15-24. doi: 10.1093/biosci/bix132

Liu, Y.-L., Chen, Y.-H., Lillywhite, H. B., and Tu, M.-C. (2012). Habitat selection by sea kraits (Laticauda spp.) at coastal sites of Orchid Island, Taiwan. Integr. Comp. Biol. 52, 274-280. doi: 10.1093/icb/ics085

Lobo, A. S., Balmford, A., Arthur, R., and Manica, A. (2010). Commercializing bycatch can push a fishery beyond economic extinction. Conserv. Lett. 3, 277-285. doi: 10.1111/j.1755-263X.2010.00117.x

Lukoschek, V. (2018a). Congruent phylogeographic patterns in a young radiation of live-bearing marine snakes: Pleistocene vicariance and the conservation implications of cryptic genetic diversity. Div. Distribut. 24, 325-340. doi: $10.1111 /$ ddi.12687

Lukoschek, V. (2018b). Population declines, genetic bottlenecks and potential hybridization in sea snakes on Australia's Timor Sea reefs. Biol. Conserv. 225, 66-79. doi: 10.1016/j.biocon.2018.06.018

Lukoschek, V., Beger, M., Ceccarelli, D., Richards, Z., and Pratchett, M. (2013). Enigmatic declines of Australia's sea snakes from a biodiversity hotspot. Biol. Conserv. 166, 191-202. doi: 10.1016/j.biocon.2013.07.004

Lukoschek, V., Heatwole, H., Grech, A., Burns, G., and Marsh, H. (2007). Distribution of two species of sea snakes, Aipysurus laevis and Emydocephalus annulatus, in the southern Great Barrier Reef: metapopulation dynamics, marine protected areas and conservation. Coral Reefs 26, 291-307. doi: 10.1007/ s00338-006-0192-8

Lukoschek, V., Osterhage, J. L., Karns, D. R., Murphy, J. C., and Voris, H. K. (2011). Phylogeography of the Mekong mud snake (Enhydris subtaeniata): the biogeographic importance of dynamic river drainages and fluctuating sea levels for semiaquatic taxa in Indochina. Ecol. Evol. 1, 330-342. doi: 10.1002/ece3.29

Lukoschek, V., and Shine, R. (2012). Sea snakes rarely venture far from home. Ecol. Evol. 2, 1113-1121. doi: 10.1002/ece3.256

Lynch, T. P. (1999). The Behavioural Ecology of the Olive Sea Snake, Aipysurus laevis. Ph.D. thesis, James Cook University of North Queensland, St Lucia, QLD.

Marshall, C. E., Glegg, G. A., and Howell, K. L. (2014). Species distribution modelling to support marine conservation planning: the next steps. Mar. Pol. 45, 330-332. doi: 10.1016/j.marpol.2013.09.003

Masunaga, G., and Ota, H. (2003). Growth and reproduction of the sea snake, Emydocephalus ijimae, in the Central Ryukyus, Japan: a mark and recapture study. Zool. Sci. 20, 461-470. doi: 10.2108/zsj.20.461

Milton, D. A., Fry, G. C., and Dell, Q. (2009). Reducing impacts of trawling on protected sea snakes: by-catch reduction devices improve escapement and survival. Mar. Freshw. Res. 60, 824-832. doi: 10.1071/ MF08221

Murphy, J. C. (2012). Marine invasions by non-sea snakes, with thoughts on terrestrial-aquatic-marine transitions. Integr. Comp. Biol. 52, 217-226. doi: $10.1093 /$ icb/ics060

Park, J., Kim, I.-H., Fong, J. J., Koo, K.-S., Choi, W.-J., Tsai, T.-S., et al. (2017). Northward dispersal of sea kraits (Laticauda semifasciata) beyond their typical range. PLoS One 12:e0179871. doi: 10.1371/journal.pone.0179871

Punay, E. (1975). "Commercial sea snake fisheries in the Philippines," in The Biology of Sea Snakes, ed. W. A. Dunson (Baltimore, MD: University Park Press), 489-502.
Pyron, R. A., Burbrink, F. T., and Wiens, J. J. (2013). A phylogeny and revised classification of Squamata, including 4161 species of lizards and snakes. BMC Evol. Biol. 13:93. doi: 10.1186/1471-2148-13-93

Rasmussen, A., Auliya, M., and Wolfgang, B. (2001). A new species of the sea snake genus Hydrophis (Serpentes: Elapidae) from a river in West Kalimantan (Indonesia. Borneo). Herpetologica 57, 23-32.

Rasmussen, A., Elmberg, J., Sanders, K., and Gravlund, P. (2012). Rediscovery of the rare sea snake Hydrophis parviceps Smith 1935: Identification and conservation status. Copeia 2012, 276-282. doi: 10.1643/ch-11-116

Rasmussen, A. R., Murphy, J. C., Ompi, M., Gibbons, J. W., and Uetz, P. (2011). Marine Reptiles. PLoS One 6:e27373. doi: 10.1371/journal.pone.0027373

Reed, R. N., Shine, R., Shetty, S., and Montgomery, W. (2002). Sea kraits (Squamata: Laticauda spp.) as a useful bioassay for assessing local diversity of eels (Muraenidae, Congridae) in the western Pacific Ocean. Copeia 2002, 1098-1101. doi: 10.1643/0045-8511(2002)002[1098:SKSLSA]2.0.CO;2

Rezaie-Atagholipour, M., Riyahi-Bakhtiari, A., Sajjadi, M., Yap, C. K., Ghaffari, S., Ebrahimi-Sirizi, Z., et al. (2012). Metal concentrations in selected tissues and main prey species of the annulated sea snake (Hydrophis cyanocinctus) in the Hara Protected Area, northeastern coast of the Persian Gulf, Iran. Mar. Pollut. Bull. 64, 416-421. doi: 10.1016/j.marpolbul.2011.11.015

Sanders, K. L., Lee, M. S. Y., Leys, R., Foster, R., and Keogh, J. S. (2008). Molecular phylogeny and divergence dates for Australasian elapids and sea snakes (hydrophiinae): evidence from seven genes for rapid evolutionary radiations. J. Evol. Biol. 21, 682-695. doi: 10.1111/j.1420-9101.2008. 01525. $x$

Sanders, K. L., Lee, M. S. Y., Mumpuni, Bertozzi, T., and Rasmussen, A. R. (2013). Multilocus phylogeny and recent rapid radiation of the viviparous sea snakes (Elapidae: Hydrophiinae). Mol. Phylogenet. Evol. 66, 575-591. doi: 10.1016/j. ympev.2012.09.021

Sanders, K. L., Mumpuni, Hamidy, A., Head, J. J., and Gower, D. J. (2010). Phylogeny and divergence times of filesnakes (Acrochordus): inferences from morphology, fossils and three molecular loci. Mol. Phylogenet. Evol. 56, 857-867. doi: 10.1016/j.ympev.2010.04.031

Sanders, K. L., Rasmussen, A. R., Elmberg, J., Mumpuni, S., Guinea, M., Blias, P., et al. (2012). Aipysurus mosaicus, a new species of egg-eating sea snake (Elapidae: Hydrophiinae), with a redescription of Aipysurus eydouxii (Gray, 1849). Zootaxa 3431, 1-18.

Sanders, K. L., Rasmussen, A. R., and Guinea, M. L. (2014). High rates of hybridisation reveal fragile reproductive barriers between endangered Australian sea snakes. Biol. Conserv. 171, 200-208. doi: 10.1016/j.biocon.2014. 01.013

Sanders, K. L., Schroeder, T., Guinea, M. L., and Rasmussen, A. R. (2015). Molecules and morphology reveal overlooked populations of two presumed extinct Australian sea snakes (Aipysurus: Hydrophinae). PLoS One 10:e0115679. doi: 10.1371/journal.pone.0115679

Senanayake, M. P., Ariaratnam, C. A., Abeywickrema, S., and Belligaswatte, A. (2005). Two Sri Lankan cases of identified sea snake bites, without envenoming. Toxicon 45, 861-863. doi: 10.1016/j.toxicon.2005.02.010

Sheehy, C. M., Solórzano, A., Pfaller, J. B., and Lillywhite, H. B. (2012). Preliminary Insights into the phylogeography of the yellow-bellied sea snake, Pelamis platurus. Integr. Comp. Biol. 52, 321-330. doi: 10.1093/icb/ics088

Simpfendorfer, C. A., Kyne, P. M., Noble, T. H., Goldsbury, J., Basiita, R. K., Lindsay, R., et al. (2016). Environmental DNA detects Critically Endangered largetooth sawfish in the wild. Endan. Spec. Res. 30, 109-116. doi: 10.3354/ esr00731

Sutherland, W. J., Freckleton, R. P., Godfray, H. C. J., Beissinger, S. R., Benton, T., Cameron, D. D., et al. (2013). Identification of 100 fundamental ecological questions. J. Ecol. 101, 58-67. doi: 10.1186/s12859-0150806-7

Sutherland, W. J., and Woodroof, H. J. (2009). The need for environmental horizon scanning. Trends Ecol. Evol. 24, 523-527. doi: 10.1016/j.tree.2009.04.008

Swan, J. M., Neff, J. M., and Young, P. C. (1994). Environmental Implications of Offshore Oil and Gas Development in Australia. The Finding of An Independent Scientific Review. Sydney, SA: Australian Petroleum Exploration Association Limited.

Tabata, R., Tashiro, F., Nishizawa, H., Takagi, J., Kidera, N., and Mitamura, H. (2017). Stomach contents of three sea kraits (Hydrophiinae: Laticauda spp.) in the Ryukyu Islands, Japan. Curr. Herpetol. 36, 127-134. doi: 10.5358/hsj.36.127 
Tan, C., Tan, N., Tan, K., and Kwong, K. (2015). Antivenom cross-neutralization of the venoms of Hydrophis schistosus and Hydrophis curtus, two common sea snakes in Malaysian waters. Toxins 7:572. doi: 10.3390/toxins7020572

Udyawer, V., Cappo, M., Simpfendorfer, C. A., Heupel, M. R., and Lukoschek, V. (2014). Distribution of sea snakes in the Great Barrier Reef Marine Park: observations from 10 yrs of baited remote underwater video station (BRUVS) sampling. Coral Reefs 33, 777-791. doi: 10.1007/s00338-014-1152-3

Udyawer, V., Read, M., Hamann, M., Heupel, M. R., and Simpfendorfer, C. A. (2016a). Importance of shallow tidal habitats as refugia from trawl fishing for sea snakes. J. Herpetol. 50, 527-533. doi: 10.1670/15-026

Udyawer, V., Read, M. A., Hamann, M., Simpfendorfer, C. A., and Heupel, M. R. (2013). First record of sea snake (Hydrophis elegans, Hydrophiinae) entrapped in marine debris. Mar. Pollut. Bull. 73, 336-338. doi: 10.1016/j.marpolbul.2013. 06.023

Udyawer, V., Simpfendorfer, C., and Heupel, M. (2015). Diel patterns in threedimensional use of space by sea snakes. Anim. Biotelemet. 3, 1-9. doi: 10.1186/ s40317-015-0063-6

Udyawer, V., Simpfendorfer, C. A., Read, M., Hamann, M., and Heupel, M. R. (2016b). Exploring habitat selection in sea snakes using passive acoustic monitoring and Bayesian hierarchical models. Mar. Ecol. Prog. Series 546, 249-262. doi: 10.3354/meps11632

Ukuwela, K. D. B., de Silva, A., Mumpuni, Fry, B. G., Lee, M. S. Y., and Sanders, K. L. (2013). Molecular evidence that the deadliest sea snake Enhydrina schistosa (Elapidae: Hydrophiinae) consists of two convergent species. Mol. Phylogenet. Evol. 66, 262-269. doi: 10.1016/j.ympev.2012.09.031

Ukuwela, K. D. B., de Silva, A., Mumpuni, Fry, B. G., and Sanders, K. L. (2014). Multilocus phylogeography of the sea snake Hydrophis curtus reveals historical vicariance and cryptic lineage diversity. Zool. Scripta 43, 472-484. doi: 10.1111/ zsc. 12070

Van Cao, N., Thien Tao, N., Moore, A., Montoya, A., Redsted Rasmussen, A., Broad, K., et al. (2014). Sea snake harvest in the Gulf of Thailand. Conserv. Biol. 28, 1677-1687. doi: $10.1111 /$ cobi.12387

Voris, H. K. (1966). Fish eggs as the apparent sole food item for a genus of sea snake, emydocephalus (Krefft). Ecology 47, 152-154. doi: 10.2307/1935755

Voris, H. K. (1985). Population size estimates for a marine snake (Enhydrina schistosa) in Malaysia. Copeia 1985, 955-961. doi: 10.2307/ 1445247

Voris, H. K., and Glodek, G. S. (1980). Habitat, diet, and reproduction of the file snake, Acrochordus granulatus, in the Straits of Malacca. J. Herpetol. 48:108. doi: $10.2307 / 1563896$

Voris, H. K., and Murphy, J. C. (2002). The prey and predators of Homalopsine snakes. J. Nat. Hist. 36, 1621-1632. doi: 10.1080/00222930110062642
Voris, H. K., and Voris, H. H. (1983). Feeding strategies in marine snakes: an analysis of evolutionary, morphological, behavioral and ecological relationships. Am. Zool. 23, 411-425. doi: 10.1093/icb/23.2.411

Ward, T. (2001). Age structures and reproductive patterns of two species of sea snake, Lapemis hardwickii (Grey 1836) and Hydrophis elegans (Grey 1842), incidentally captured by prawn trawlers in Northern Australia. Mar. Freshw. Res. 52, 193-203. doi: 10.1071/MF00025

Wassenberg, T. J., Milton, D. A., and Burridge, C. Y. (2001). Survival rates of sea snakes caught by demersal trawlers in northern and eastern Australia. Biol. Conserv. 100, 271-280. doi: 10.1016/S0006-3207(01)00031-3

Westhoff, G., Fry, B. G., and Bleckmann, H. (2005). Sea snakes (Lapemis curtus) are sensitive to low-amplitude water motions. Zoology 108, 195-200. doi: 10.1016/ j.zool.2005.07.001

Zhou, S. J., Milton, D. A., and Fry, G. C. (2012). Integrated risk analysis for rare marine species impacted by fishing: sustainability assessment and population trend modelling. ICES J. Mar. Sci. 69, 271-280. doi: 10.1093/icesjms/fss009

Zimmerman, K., and Heatwole, H. (1990). Cutaneous photoreception: a new sensory mechanism for reptiles. Copeia 1990, 860-862. doi: 10.2307/ 1446454

Zimmerman, K., Watters, D., Hawkins, C., and Heatwole, H. (1993). Effects of fractions isolated from venom of the olive sea snake, Aipysurus laevis, on the behavior and ventilation of a prey species of fish. J. Nat. Toxins 2, 175-186.

Zimmerman, K. D., Heatwole, H., and Davies, H. I. (1992). Survival times and resistance to sea snake (Aipysurus laevis) venom by five species of prey fish. Toxicon 30, 259-264. doi: 10.1016/0041-0101(92)90868-6

Zimmerman, S. E., Heatwole, H. H., Andreopoulos, P. C., and Yong, L. C. J. (1992). Proliferative glomerulonephritis in mice induced by sea snake (Aipysurus laevis) venom. Exp. Toxicol. Pathol. 44, 294-300. doi: 10.1016/S0940-2993(11)80250-2

Conflict of Interest Statement: The authors declare that the research was conducted in the absence of any commercial or financial relationships that could be construed as a potential conflict of interest.

Copyright (c) 2018 Udyawer, Barnes, Bonnet, Brischoux, Crowe-Riddell, D’Anastasi, Fry, Gillett, Goiran, Guinea, Heatwole, Heupel, Hourston, Kangas, Kendrick, Koefoed, Lillywhite, Lobo, Lukoschek, McAuley, Nitschke, Rasmussen, Sanders, Sheehy, Shine, Somaweera, Sweet and Voris. This is an open-access article distributed under the terms of the Creative Commons Attribution License (CC BY). The use, distribution or reproduction in other forums is permitted, provided the original author(s) and the copyright owner(s) are credited and that the original publication in this journal is cited, in accordance with accepted academic practice. No use, distribution or reproduction is permitted which does not comply with these terms. 